\title{
Venous Stroke
}

National Cancer Institute

\section{Source}

National Cancer Institute. Venous Stroke. NCI Thesaurus. Code C116715.

Ischemic or hemorrhagic stroke resulting from cerebral venous thrombosis. 